\title{
A Transactional Model of Learning and Intelligence
}

\author{
Henry Jefferson Grubb \\ Professor of Psychology, University of Dubuque, 2000 University Avenue Dubuque, IA 52001 \\ *Corresponding Author: hgrubb@dbq.edu
}

Copyright (C) 2013 Horizon Research Publishing. All rights reserved.

\begin{abstract}
A transactional model of intelligence is contrasted with main-effect and interactional models through the examination of perhaps the most important source of biological and social-cultural determinants to intellectual behavior; the family of origin. This examination allows the science of cognition both an understanding of intelligence and the development of intelligence. A method of investigation of intellectual development and cognitive science's ability to understand intelligence and learning is suggested.
\end{abstract}

Keywords Intelligence, Development, Transactional, Cognition, Family

\section{A Transactional Model of Learning and Intelligence}

A developmental model of intelligence would be a transactional model. It would include biological and environmental factors in a synergistic approach to the question. The combination of biological, environmental, nutritional, cultural, and social factors would be interactive, one upon all others, and the effect of all on intelligence would be more than the sum of effects of the individual determinants. Teasing out which variables influencing intelligence predate other factors would be a very difficult operation because all the important variables are active (or possess the potential to be active) at all stages of an organism's life, as will become evident from the text that follows. Even before the neonatal period (and even prior to conception) the entire range of controlling variables are already operative in mutual multi-dimensional dialectics, constantly being transformed and constantly transforming.

\section{Introduction}

To begin understanding intelligence in the individual human, one must first understand intelligence in the human species. Hall, Lamb, and Perlmutter (1982) identify species intelligence as "the disposition to behave adaptively when faced with the demands of the environment." They further state that as a species moves up the phylogenic ladder, becoming more intelligent, the amount of learned behavior increases while the percentage of instinctual behavior declines. Mankind can therefore be viewed as an animal slighted by nature in the fixed knowledge area, those few traits considered instinctual to the species being quite evenly distributed throughout the population by the process of natural selection (Hall, Lamb, and Perlmutter, 1982; Hamilton, 1964).

Watson goes as far as to state "there are no instincts or inherited capacities or talents of any kind (endowed by evolution on humankind)" (Schultz and Schultz, 2011). Because of the peculiar evolutionary niche in which mankind has been driven, the species lives in a symbolically created universe in which each member organism must "learn" as it develops. This is not to say that there are no biological factors still at work in the formation of adult Intelligence but that human Intelligence is radically different from that under which the vast majority of earthly species operate. Human intelligence and learning is influenced by the individual's genetic inheritance through interaction with the socially constructed environment, not through direct species-specific behavioral directives, as in lower organisms.

\section{Literature Review}

One important source of biological determinants to Intellectual behavior is the immediate family of origin. Humans selectively mate. Lower socio-economic status (SES) persons usually mate with members of their own class, Blacks usually mate with other Blacks, and tall females usually mate with tall men. Even though all this selective mating is intertwined with social and cultural mores, traditions, and even legal statutes, the effect of one function upon the other, and specifically the biological cause and consequence is undeniable. Zeskin and Ramey (1981) investigated the maternal history of infants with low Rohrer's ponderal indexes (PI) and found that, compared to matched control's, these mothers had significantly lower IQs (as measured on the WAIS), more obstetric problems, (miscarriages and premature births), and more health related problems. The evidence would seem to suggest that those mothers with lower adult intellectual functioning tend to rear 
more children on the same order, if no outside intervention is provided.

When considering family history it is of course necessary to examine the environmental aspects of intellectual development in conjunction with the biological. Herein lies the usefulness of a transactional model of development over main-effect and interactional models. A transactional view sees the two processes, to use a chemical analogy, not as a mixture with each substance retaining its original significance and quantifiable in percentage contribution, but as a compound - each substance entering a relationship with the other in which both are transformed to form a new entity. Transactions arise centered around the interface of the biological and environmental spheres that give rise to a dynamic interplay of interpersonal relationships which foster the propagation of a vicious positive feedback loop, maintaining and enhancing the original biological and environmental interactions intergenerationally.

By manipulating only certain environmental aspects, which correlate with depressed infant intellectual behavior, Zeskind and Ramey $(1978,1981)$ were able to demonstrate that the control of one part of a dynamic assemblage produced a synergistic change in the desired direction on performance measures. Simple addition of outside (non-maternal) positive interpersonal interaction with very young infants ameliorated the devastating effects of poverty, poor parenting skills, and other negative intergenerational influences. This result was possible, to rarefy the parlance of transactionalism, because the whole is more than the sum of the parts and therefore the removal of any part radically changes the quality of the whole. Only a transactional model would predict such an outcome.

Keeping in mind that all variables impacting on the development of intelligence are transformed continually by the transactions taking place between them and other variables at work, it is now possible to list some of the various known determinants and their "singular" effects on IQ. Factors such as sex, SES (Socioeconomic status), region of residence, and the urban-rural dichotomy have been shown to affect what an individual knows as measured on standardized tests of intellectual ability (Reynolds and Nigl, 1981; Kaufman and Kaufman, 1973). Males and females learn different behavior in our society but the material on IQ tests are so constructed that no difference between the sexes is apparent on the most widely used assessment instruments (Hall, Lamb, and Perlmutter, 1982; Taylor, 1976). The SES of a child's family of origin is directly correlated with IQ scoring, whereas city dwellers outscore cohorts living in rural areas and those children living in the North and East outperform those being raised in the South and West. The absence of a father has been found to correlate directly with lower IQ in most studies (Greenberg and Davidson, 1972; Carter and Walsh, 1980; Deutsch, 1960). The educational level of a child's parents (especially that of a present father on his son (Hall, Lamb, and Perlmutter, 1982)) also has a direct correlation with the child's measured IQ (Greenberg and Davidson, 1972). The number of children in the family is inversely correlated with performance on tests of intellect (Olneck and Bills, 1971) as is the person/room ratio in the home (Greenberg and Davidson, 1972). Educational levels of the teachers in the school where a child attends is also correlated with the IQ of the child - directly (Lindsay, 1980); an obvious but often overlooked fact.

Malnourishment either pre- or post-natally has been shown to have a detrimental effect on IQ (Birch, 1972) as has many forms of infection, disease, and certain handicaps (Hall, Lamb, and Perlmutter, 1982). Blind and deaf children learn at different rates and have knowledge of their environment that is not the same as that of non-handicapped siblings. This partly explains their collective poorer performance on standardized measures of intelligence. These indices are not constructed to measure handicapped individuals compensatory intelligences. There is a similar failing of standard measures of intelligence to adequately assess the true range of intellectual behavior in other sub-populations learning a host of skills useful within their social-cultural niche in the larger society (Grubb and Dozier, 1989).

Many investigators are currently cataloguing the environmental (and biological) agents that affect intellectual growth. The listing given above is by necessity incomplete and only set down in order to give the reader an idea of the diversity of the influences affecting the topic behavior. The author is particularly interested in the compilation of the environmental variables, even going so far as to believe that all the variables will ultimately be determined to be environmental based on the current thinking in social biology (Hamilton, 1964). Even those inherited, genetic and biological variables affecting intelligence can ultimately be described as socio-culturally and environmentally derived. Since the individual's IQ score is dependent on both the biological health of the family and its insistence of formal education (motivational factors), its position within the supraculture, and therefore access to middle-class information contained on the normative measuring instrument, and the amount of distracting knowledge necessary for the individual but not measured by the index, all responses can be seen as cultural (environmental) (Berry, Poortinga, Segall, and Dasen, 1992).

Knowledge and listing of those environmental influences does not lead one to an understanding of how intelligence develops however. This point is another deficit in main effect and interactional models of development - they only catalogue those variables correlated with intelligence. Jensen (1969), a leading proponent of the hereditary main effect model, can even feel free to claim that 80-percent of the difference between individuals is the result of genetics, even though most experts in the field propose a much lower figure: $50 \%$ (Hockenbury and Hockenbury, 2007) or $40 \%$ (Henderson, 1982; Plomin, 1990). A close inspection of his theoretical formulation will clearly prove the fallacy of his assumptions (Conwill, 1980; Taylor, 1979), however he shares one problem common to all non-transactional developmental psychologists; the mere knowledge of what factors correlate with intellectual development does not 
explain how those same factors influence the development of intelligence. A transactional model does. Just knowing that educational level of parents and family income positively correlates with IQ scores only suggests how they might be related when examined for either a main-effect or interactional point of view. But if one were to posit on-going additive transactions between income, parental educational level, the family (microsystem), the micro - and macro-systems across time (chronosystem) and how these positive feedback loops control IQ test score responses, one not only understands that score but its development.

\section{Discussion \& Conclusion}

Based on an amalgamation of Piagetian, learning, and information processing theories one can formulate a transactional model of intellectual development. Piaget provides a rather complete listing of the different stages infants and children traverse in order to develop adult intellectual behavior (Piaget, 1972). The famous theorist begins this developmental journey at birth. Although it can effectively be argued that the development of intelligence has already been in progress for some nine months, little experimental data has been accumulated concerning the development of intelligence in the intrauterine human. But this is changing (Lecanuet, Krasnegor, and Fifer, 1995).

Learning-based theory allows one to understand the mechanisms involved in the acquisition of discrete bits of information by the individual. Within the cognitive framework of a sub-stage's schema, learning theory is quite effective in detailing how new behaviors are added to ones repertoire or how old behaviors are modified or lost. Concepts such as operant and classical conditioning, reinforcement schedules, and extinction go far to explain intellectual change and development. Broadening learning theory to include social learning concepts such as modeling and attribution allows a clear view of the process of development at work.

When the information-processing approach is also added to the equation, greater understanding of the acquisition of intelligence is gained, but more importantly, some insight into the transmutation of the Piagetian stages is revealed. Gagne (1968), a learning theorist, believes that children do not shift magically from one stage to the next but that slow cumulative learning explains the switch from pre-operational to concrete operational stages, for instance. Sternberg (1977) makes a subtler and more convincing argument when he tackles the distinction between learning (intra-stage acquisition of knowledge) and development (the reorganization of one's schemas). Sternberg believes learning principles can explain the former while meta-learning is required to explain the later.

A child learns how to push a ball off a table by trial-and-error, reinforcement, and driven by curiosity (learning) but a child moves from the sensorimotor stage to the preoperational stage by constant repetition of the learning paradigms until an understanding of what is learned - is learned. Meta-learning is therefore knowledge of knowledge. Sternberg (1979) believes that once one begins to analyze intelligence at the meta-learning or meta-knowledge level (his term: metacomponents), one will be able to more fully grasp the concept of intelligence, its hows and whys and lay down principles as firm as those already laid down at the learning level. The cross-cultural perspective, often termed the forth force in psychology, gives the cognitive psychologist the ability to examine even the construct of intelligence, as all cognition, as culturally derived. The cross-cultural scientist can step back from the test scores and other behaviors deemed intellectual and examine the social cultural and environmental transactions that lead to this measured end point.

\section{Recommendation}

It is suggested that experimentation now be conducted to determine how one correlate relates to (is changed by, changes) other correlates of intelligence. Now that the field of cognitive psychology possesses a good amount of knowledge on simple effects of various environments on the development of intelligence, it is time to manipulate the interaction of these settings in order to determine their transactional effect on intelligence. Only then will one be able to say more than what is intelligence (the ability to learn). Then the field will move toward defining the process of intelligence (the ability to know the ability to learn) and the process of the development of intelligence (the ability to understand the formation of the ability to know the ability to learn). This will go far in taking psychology away from inferring intelligence arising out of simple biological, social, nutritional, or even combination/interaction of such static factors. A transactional paradigm will actually precipitate the expected outcome suggested above, a constantly arising, constantly changing view of intelligence and ability to learn.

\section{REFERENCES}

[1] Berry, J.W., Poortinga, Y. H., Segall, M. H., \& Dasen, P.R. Cross-Cultural Psychology: research and application. New York: Cambridge University Press. 1992.

[2] Birch, H.G. (1972). Malnutrition, learning, and intelligence. American Journal of Public Health, 1972, 62, 773-784.

[3] Carter, D.E., \& Walsh, J.A. (1980). Father absence and the black child; a multivariate analysis. Journal of Negro Education, 49(2) 134-143.

[4] Convillo W.L. (1980). The inheritance of IQ and scholastic achievement: further comments on the Jensen article.* Journal of Negro Education, 1980, 49(1), 97-104.

[5] Deutsch, M. (1960). Minority group and class status as related to social and personality factors in scholastic 
achievement. Monographs of Sociology and Applied Anthropology,2, 1-32.

[6] Gagne, R.M. (1968). Contributions of learning to human development. Psychological Review, 75, 177-191.

[7] Greenberg, J.W. and Davidson, H.H. (1972). Home background and school achievement of Black urban ghetto children. American Journal of Ortho-psychiatry, 42, (5), 803-810.

[8] Grubb, H. J. \& Dozier, A. (1989). Too Busy to learn: a "competing behaviors" explanation of cross-cultural differences in academic ascending based on the cultural distance hypothesis. The Journal of Black Psychology, 16 (1), 23-24

[9] Hall, E., Lamb, M.E., \& Perlmutter, M. (1982). Child Psychiatry Today. New York, NY: Random House.

[10] Hamilton, W.D. (1964). The genetic evolution of social behavior (I). The Journal of Theoretical Biology, 7, 1-25.

[11] Henderson, N. D. (1982). Human Behavior Genetics. Annual Review of Psychology, 33, 403-440.

[12] Hockenbury, D. H. \& Hockenbury, S. E. (2007). Discovering Psychology (4th ed.). New York, NY: Worth.

[13] Jensen, A.R. (1969). How much can we boost IQ and scholastic achievement? Harvard Education Review, 39, $1-123$.

[14] Kaufman, A.S. \& Kaufman, N.L. (1979). Black-white differences at ages $2 \frac{1}{2}-8 \frac{1}{2}$ on the

[15] McCarthy scales of children's abilities. Journal of School Psychology, 11, 196-206.

[16] Lecanuet, J.-P., Krasnegor, N. A., \& Fifer, W. P. (Editors). (1995). Fetal Development: A Psychological Perspective. Philadelphia, PA: Taylor and Francis.
[17] Lindsay, B. Educational testing in Kenya. (1980). Journal of Negro Education, 49 (3), 274-288.

[18] Olneek, M.R. \& Bills, D.B. (1979). Family configuration and achievement; effects of birth order and family size in a sample of brothers. Social Psychology Quarterly, 42, 135-148.

[19] Piaget, J. The Psychology of the Child. (1972). New York, NY: Basic Books.

[20] Plomin, R. (1990). Nature and Nurture: An Introduction to Human Behavioral Genetics.Pacific Grove, CA: Brooks/Cole.

[21] Reynolds, C.R. \& Nigl, A.J. (1981). A regression analysis of differential validity in intellectual assessment for Black and White inner city children. Journal of Clinical Child Psychology, 10, 176-179.

[22] Schultz, D.P. \& Schultz, S.E. (2011). A History of modern psychology (10th Ed.). Stamford,Conn.: Cengage Learning.

[23] Sternberg, R.J. (1977). Intelligence, information processing, and analogical reasoning: the componential analysis of human abilities. Hillsdale, N.J.: Lawrence Erlbaum.

[24] Sternberg, R.J. (1979, September). Stalking the IQ quark. Psychology Today, 13, 42-54.

[25] Taylor, H.F. (1976). IQ heritability: a checklist of methodological fallacies. The Journal of Afro-American Issues, 4 (1), 35-49.

[26] Zeskind, P.S. \& Ramey, C.T. (1978). Fetal malnutrition: an experimental study of its consequence on infant development in two caregiving environments. Child Development, 49, 1155-1162.

[27] Zeskind, P.S. \& Ramey, C.T. (1981). Intellectual and interactional sequelae of fetal malnutrition: a longitudinal, transactional, and synergistic approach to development. Child Development, 52, 213-218. 